\title{
BIOGEOQUIMICA ESPAÇO-TEMPORAL DA LITEIRA EM AMBIENTE DE FLORESTA NATURAL NA AMAZÔNIA CENTRAL
}

\author{
Ananda Gabrielle de Matos Rebêlo ${ }^{\mathrm{a}, *,([)}$, Maria Terezinha Ferreira Monteiro ${ }^{\mathrm{a}}$, Sávio José Filgueiras Ferreira ${ }^{\mathrm{a}}$, Eduardo \\ Antonio Ríos Villamizara, Ézio Sargentini Juniorb, Marcos Alexandre Bolson ${ }^{\mathrm{b}}$ e Sergio Duvoisin Junior ${ }^{\mathrm{c}}$ \\ aDepartamento de Hidrobiogeoquímica, Instituto Nacional de Pesquisas da Amazônia, 69067-375 Manaus - AM, Brasil \\ 'Departamento de Química, Universidade do Estado do Amazonas, 69020-070 Manaus - AM, Brasil \\ 'Departamento de Química, Instituto Nacional de Pesquisas da Amazônia, 69067-375 Manaus - AM, Brasil
}

Recebido em 12/02/2021; aceito em 07/06/2021; publicado na web em 29/06/2021

\begin{abstract}
SPACE-TEMPORAL BIOGEOCHEMISTRY OF THE LITTER IN A NATURAL FOREST ENVIRONMENT IN THE CENTRAL AMAZON. This research was aimed to evaluate the concentration of 15 chemical elements as a reference base for the quality of the litter in a forest in the central region of the Amazon. The sampling of the litter was performed monthly in two topographic positions for one year. For the quantification of the elements, digestion by nitroperchloric solution and reading by ICP OES were performed. The mean of macronutrient contents in the litter in decreasing order were $\mathrm{Ca}>\mathrm{K}>\mathrm{Mg}>\mathrm{Na}$. For micronutrients, the order was $\mathrm{Al}>$ $\mathrm{Mn}>\mathrm{Fe}>\mathrm{Sr}>\mathrm{Zn}>\mathrm{Cu}>\mathrm{Ba}>\mathrm{Cr}>\mathrm{Ni}>\mathrm{Co}>\mathrm{Cd}$ for the $\mathrm{Plateau}$ and $\mathrm{Al}>\mathrm{Mn}>\mathrm{Fe} \mathrm{Sr}>\mathrm{Zn}>\mathrm{Cu}>\mathrm{Ba}>\mathrm{Cr}>\mathrm{Ni}>\mathrm{Cd}>\mathrm{Co}$ for the $\mathrm{Baixio}$. Among the fractions, calcium had its highest concentration in the woody material, potassium in the reproductive material, while magnesium, sodium, and aluminum showed higher concentrations in the leaf fraction. Also, it was observed that the return of the elements to the soil by litter was greater in the dry period of the region, due to the greater fall in plant material. Calcium differed significantly within the same area, obtaining the highest concentrations compared to the other elements, while aluminum and zinc differed significantly between the areas studied, with a higher return for both elements on the Plateau.
\end{abstract}

Keywords: elements; litter; reference values; natural forest.

\section{INTRODUÇÃO}

A biomassa vegetal assume papel importante em solos altamente intemperizados, pois permite que árvores, especialmente espécies nativas de florestas naturais da Amazônia tropical, possam reciclar nutrientes por meio da síntese de matéria orgânica através da fotossíntese. ${ }^{1}$ Para avaliar a ciclagem de nutrientes ou os chamados ciclos biogeoquímicos sobre ecossistemas tropicais brasileiros, é necessário obter informações sobre a concentração dos elementos e os fluxos pelos quais eles transitam no sistema solo-planta-solo, os quais podem ser conhecidos por meio da dinâmica da liteira, que tem sido o ponto de partida para a compreensão desse processo.

A liteira é constituída por todo material de origem vegetal (folhas, galhos, frutos, flores e outras partes das plantas) e de origem animal (carcaças e fezes, por exemplo) que se acumula sobre o solo e serve como fonte de energia e nutrientes para seres decompositores e para a vegetação. ${ }^{2}$ A formação da camada ou tapete de liteira depende basicamente da quantidade de resíduos orgânicos despejada da parte aérea das plantas e da taxa de decomposição desses resíduos. Esse tapete formado pela liteira e a devolução de elementos químicos em ecossistemas florestais constituem, portanto, a via mais importante do ciclo biogeoquímico de nutrientes. ${ }^{3}$

Um dos métodos não destrutivos de avaliação da produtividade e qualidade de um ecossistema florestal é realizado por meio de monitoramentos da dinâmica da liteira. Ele, quando associado a outras variáveis, permite observar e analisar a resposta da floresta às tensões sofridas, quer sejam elas bióticas ou abióticas. O padrão de distribuição espacial e temporal da liteira é um importante e eficiente indicador da função dos ecossistemas com relação aos estoques e fontes de nutrientes, pois permitem identificar aspectos da estabilidade da vegetação e interação desta com o clima. ${ }^{4}$
Estudos que avaliam o fluxo de liteira são de grande interesse, especialmente em ecossistemas da Amazônia, cuja maior contribuição seria avaliar esse padrão em diferentes regimes de uso do solo. ${ }^{5} \mathrm{O}$ conhecimento de teores naturais possibilita ainda a definição de padrões de qualidade do solo, assim como a avaliação do potencial de suprimento de nutrientes na vegetação, além do fornecimento de informações base para projetos de recuperação de áreas degradadas. ${ }^{6-8}$

Os elementos químicos essenciais são classificados em macro e micronutrientes, de acordo com a concentração encontrada no tecido das plantas. Os macronutrientes são empregados em maior quantidade pelos vegetais, sendo eles $\mathrm{Ca}, \mathrm{K}$ e $\mathrm{Mg}$, enquanto os micronutrientes, como $\mathrm{Cu}, \mathrm{Fe}, \mathrm{Mn}$, Ni e $\mathrm{Zn}$, são exigidos em menor quantidade. ${ }^{9,10}$ Além disso, existem elementos que não são essenciais para plantas, e caso sejam encontradas em concentrações elevadas, podem ser considerados tóxicos, como é o caso dos metais $\mathrm{Na}, \mathrm{Co}, \mathrm{Al}, \mathrm{Ba}$, $\mathrm{Cr}, \mathrm{Sr}, \mathrm{Cd}$ e Na. Todos esses elementos variam muito de um solo para outro e entre diferentes plantas. Portanto, uma comparação da concentração desses elementos em diferentes tipos de vegetação e em diversas regiões, gera uma gama de resultados diversos sem relação aparente. Desse modo, os valores obtidos neste estudo, permitem a comparação deste com ambientes da mesma região, uma vez que ainda não existe, para o Estado do Amazonas, valores aceitáveis de limites desses elementos na liteira.

Diante desse cenário, e reconhecendo a importância de estudos como esse em florestas nativas sem intervenção antrópica, o objetivo do trabalho foi avaliar a concentração de 15 elementos químicos da liteira em ambiente natural não antropizado localizados em diferentes perfis topográficos (platô e baixio) em uma microbacia do Estado de Amazonas, visando caracterizar a ocorrência dos teores desses elementos.

*e-mail: agmrebelo@gmail.com 


\section{PARTE EXPERIMENTAL}

\section{Área de estudo e caracterização fisiográfica}

O estudo foi realizado em uma área de pesquisa do Programa de Grande Escala da Biosfera-Atmosfera na Amazônia (LBA) do Instituto Nacional de Pesquisas da Amazônia (INPA), localizada a $60 \mathrm{~km}$ ao norte da cidade de Manaus. A Reserva Biológica do Cuieiras fica localizada em uma área de floresta primária medindo cerca de 22.735 ha (Figura 1), possui uma média anual de precipitação de $2.524 \mathrm{~mm}$, com uma estação seca de julho a novembro. Pela classificação de Köppen o clima é do tipo "Am", conceituado como megatérmico (tropical úmido). A média anual de temperatura é de $26^{\circ} \mathrm{C}$ com temperatura média do mês mais frio acima de $18{ }^{\circ} \mathrm{C}$. A variação térmica diurna é bem maior do que a anual, com temperatura média mínima e máxima entre $23,5^{\circ} \mathrm{C}$ e $31,2^{\circ} \mathrm{C}$, respectivamente. Em valores médios mensais, a temperatura varia de um mínimo de $24,5^{\circ} \mathrm{C}$ na estação chuvosa, para pouco mais de $27{ }^{\circ} \mathrm{C}$ na estação seca. ${ }^{11}$

\section{Amostras de liteira}

As amostras de produção de liteira utilizadas neste estudo foram coletadas no ano de 2009 em duas posições topográficas (platô e baixio). Cada área possuía 3 sub-parcelas de $20 \times 80 \mathrm{~m}$, sendo que em cada sub-parcela continham 10 coletores de pvc $(50 \times 50 \mathrm{~cm})$ distribuídos aleatoriamente na área, com fundo de tela de náilon ( $1 \mathrm{~mm}$ de malha) distante $50 \mathrm{~cm}$ do solo. As amostras foram coletadas mensalmente. $\mathrm{O}$ material coletado foi submetido a uma secagem ao ar, para que não se deteriorem devido ao alto teor de umidade, limpas com um pincel para evitar contaminações por terra ou outras impurezas e em seguida triado em: folhas, material lenhoso (galhos finos e pedaços do tronco), material reprodutivo (flores, frutos e sementes) e resíduos (material fecal, insetos e materiais não identificados). Após a triagem, todo material foi colocado para secar em estufa a $65-70{ }^{\circ} \mathrm{C}$ até atingir um peso constante. ${ }^{12}$

Após atingirem o peso constante, as amostras foram pesadas em balança de precisão (dados em Conceição), ${ }^{12}$ moídas em moinho tipo Willey, com facas e câmara de aço inoxidável e com peneiras de 0,5 ou $1 \mathrm{~mm}$ de diâmetro, visando assegurar a homogeneização da amostra. Em seguida, as amostras foram acondicionadas em frascos plásticos com tampa hermética para evitar qualquer contaminação e armazenadas em um local fresco e seco, ao abrigo da luz.

\section{Digestão total das amostras de liteira e controle de qualidade das análises}

Para a digestão total das amostras de liteira foi feita uma amostra composta de cada subárea, totalizando 3 amostras por gradiente topográfico de cada fração. Pesou-se, em papel-manteiga, $0,5 \mathrm{~g}$ de material vegetal moído, sendo ele transferido cuidadosamente para um tubo de digestão. $\mathrm{O}$ material moído foi submetido à digestão nitroperclórica (ácido nítrico (65\% v/v) e ácido perclórico (70\% v/v), Merck - 3:1), segundo metodologia descrita por Malavolta et al. ${ }^{9}$ Após a transferência do material para os tubos de digestão, adicionaramse $6,0 \mathrm{~mL}$ de ácido nítrico $\left(\mathrm{HNO}_{3}\right)$, no qual foi deixado em repouso por 12 horas para a digestão prévia. Esse método apresenta maior eficiência de extração de macro e micronutrientes em tecido vegetal, e menor variação em relação aos demais métodos. Os tubos de digestão foram transferidos para um bloco digestor macro modelo $2350.8 \mathrm{em}$ uma capela de exaustão, o controle da temperatura foi programado da seguinte forma: $1^{\mathrm{a}}$ temperatura de $60{ }^{\circ} \mathrm{C}$, com permanência de $30 \mathrm{~min} ; 2^{\mathrm{a}}$ temperatura de $120^{\circ} \mathrm{C}$, com permanência até cessar o desprendimento do gás de coloração castanho $\left(\mathrm{NO}_{2}\right) ; 3^{\mathrm{a}}$ temperatura de $180{ }^{\circ} \mathrm{C}$, no qual adicionou-se $2,0 \mathrm{~mL}$ de ácido perclórico $\left(\mathrm{HClO}_{4}\right) ; 4^{\mathrm{a}}$ temperatura de $210{ }^{\circ} \mathrm{C}$, com permanência suficiente para o início do desprendimento do gás de coloração branca. Após o resfriamento, os extratos contidos nos tubos foram diluídos com
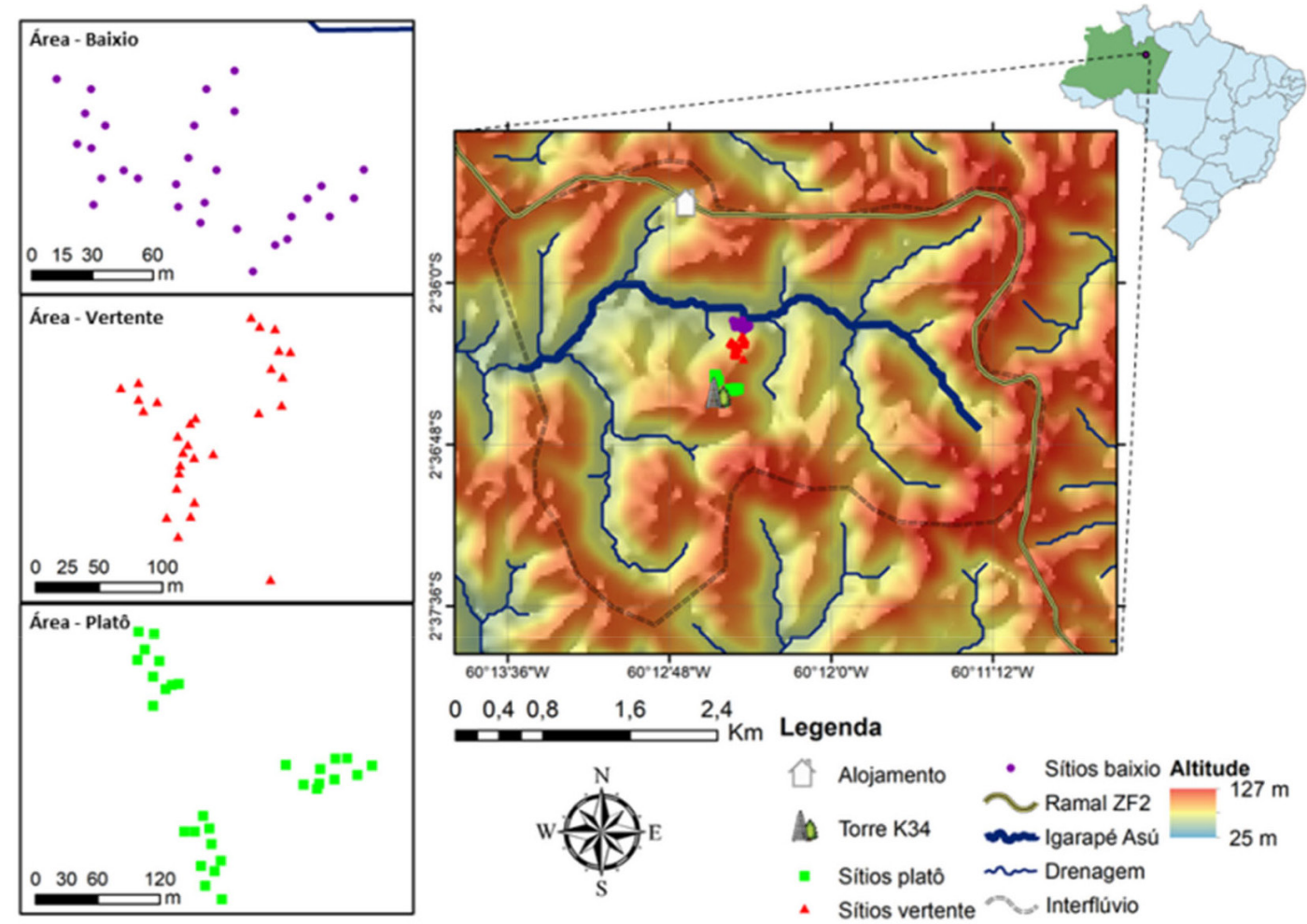

Figura 1. Área de estudo e pontos de amostras dos coletores de liteira da Microbacia Experimental do Igarapé Asú. Fonte: Regison Oliveira - Engenheira Ambiental (2019) 
água destilada em balões volumétricos de $50,00 \mathrm{~mL}$. As amostras foram homogeneizadas e transferidas para tubos falcon $(25,00 \mathrm{~mL})$ para posterior determinação analítica.

As soluções estoque (1000 $\left.\mathrm{mg} \mathrm{L}^{-1}\right)$ de $\mathrm{Ca}, \mathrm{Mg}, \mathrm{K}, \mathrm{Al}, \mathrm{Ba}, \mathrm{Co}$, $\mathrm{Cr}, \mathrm{Cu}, \mathrm{Fe}, \mathrm{Mn}, \mathrm{Ni}, \mathrm{Sr}, \mathrm{Zn}, \mathrm{Cd}$ e $\mathrm{Na}$ foram preparadas a partir de padrões Titrisol (Merck). As soluções padrão foram preparadas em balões volumétricos de 50,00 mL. Para todas as soluções padrão, adicionaram-se $20 \mathrm{~mL}$ de uma solução nitroperclórica antes do acerto do menisco, visando ajustar a matriz dos padrões às matrizes das amostras que foram digeridas na presença de solução nitroperclórica.

Os ácidos utilizados nas análises possuíam elevada pureza. Todas as soluções foram preparadas em água ultrapura. Para limpeza e descontaminação as vidrarias foram mantidas em solução de ácido nítrico $5 \%$ por 24 horas e enxaguadas com água destilada.

\section{Determinação dos elementos na liteira por espectrometria de emissão óptica}

A quantificação dos elementos químicos foi efetuada por espectrometria de emissão óptica com plasma indutivamente acoplado (ICP OES 7600, Thermo Scientific) com modo de observação dupla (axial e radial) no Laboratório em Química Analítica e Ambiental (COTI/INPA). A descrição detalhada do equipamento e os parâmetros de operação avaliados estão apresentados na Tabela 1. Todas as medidas foram realizadas usando argônio como gás para formar o plasma. O modo de observação dos elementos no plasma variou de acordo com a concentração esperada nas amostras. A configuração na axial permite uma leitura com maior sensibilidade e menor limite de detecção comparado ao modo radial. A escolha do modo de observação do equipamento foi feita de acordo com os teores médios de metais em liteira verificados em análises-teste prévias para ajuste das leituras no aparelho. ${ }^{13}$

Os comprimentos de onda (nm) utilizados e o modo de observação foram: Ca (393,366; Radial), Mg (280,270; Radial), K (766,490; Axial); Al (396,152; Axial), Ba (455,403; Radial), Co (228,616; Axial), Cr (267,716; Axial), Cu (327,396; Axial), Fe (238,204; Axial), Mn (257,610; Axial), Ni (231,604; Axial), Sr (407,771; Radial), Zn (206,200; Axial), Cd (228,802; Axial) e Na (589,592; Axial).

Tabela 1. Condições de operação do ICP OES

\begin{tabular}{lc}
\hline Parâmetros & Condições \\
\hline Potência de RF $(\mathrm{W})$ & 1150 \\
Vazão de argônio do plasma & $12 \mathrm{~L} \mathrm{~min}^{-1}$ \\
Vazão de nebulização & $0,5 \mathrm{~L} \mathrm{~min}^{-1}$ \\
Vazão de amostragem & $1 \mathrm{~mL} \mathrm{~min}^{-1}$ \\
Nebulizador & Concêntrico \\
\hline
\end{tabular}

Validação do método, limites de detecção e quantificação

Para a exatidão dos teores de nutrientes nas folhas, utilizaram-se amostras de padrão vegetal de referência interlaboratorial da Esalq, obtendo-se uma recuperação média de 84 a $99 \%$ para os elementos nas folhas, estando dentro dos intervalos admitidos como normais para a amostra. Os limites de detecção (LD) e limite de quantificação (LQ) foram calculados com base no desvio-padrão (DP) usando as seguintes equações: ${ }^{14}$

$$
\begin{gathered}
L D=\left(3 \times D P_{\text {branco }}\right) / S \\
L Q=\left(10 \times D P_{\text {branco }}\right) / S
\end{gathered}
$$

em que S é a inclinação da curva analítica.

Os valores de LD e LQ para os 15 analitos são mostrados na Tabela 2.
Tabela 2. Valores de limite de detecção (LD) e limite de quantificação (LQ) para os 15 elementos químicos analisados

\begin{tabular}{ccc}
\hline & $\mathrm{LD}\left(\mathrm{mg} \mathrm{kg}^{-1}\right)$ & $\mathrm{LQ}\left(\mathrm{mg} \mathrm{kg}^{-1}\right)$ \\
\hline $\mathrm{Ca}$ & 0,0066 & 0,0220 \\
$\mathrm{Mg}$ & 0,0003 & 0,0010 \\
$\mathrm{~K}$ & 0,0016 & 0,0053 \\
$\mathrm{Al}$ & 0,0006 & 0,0020 \\
$\mathrm{Ba}$ & 0,0011 & 0,0035 \\
$\mathrm{Co}$ & 0,0002 & 0,0008 \\
$\mathrm{Cr}$ & 0,0008 & 0,0027 \\
$\mathrm{Cu}$ & 0,0015 & 0,0050 \\
$\mathrm{Fe}$ & 0,0015 & 0,0050 \\
$\mathrm{Mn}$ & 0,0003 & 0,0010 \\
$\mathrm{Ni}$ & 0,0004 & 0,0014 \\
$\mathrm{Sr}$ & 0,0003 & 0,0010 \\
$\mathrm{Zn}$ & 0,0002 & 0,0006 \\
$\mathrm{Cd}$ & 0,0006 & 0,0020 \\
$\mathrm{Na}$ & 0,0003 & 0,0010 \\
\hline
\end{tabular}

\section{Análise dos resultados}

A liberação de nutrientes da liteira foi comparada por ANOVA simples entre os meses do ano e entre áreas para cada elemento. Quando os tratamentos apresentaram diferenças significativas $(\mathrm{p}<0,05)$, foi aplicado o teste de Tukey. Todas as análises se deram pelo soft Excel e OriginPro.

\section{RESULTADOS E DISCUSSÃO}

\section{Concentração dos elementos químicos na liteira produzida}

A liteira, por ser a principal via de transferência de matéria orgânica, é utilizada para comparar a disponibilidade e a eficiência de utilização de elementos químicos em diferentes florestas. Há uma grande variação quanto à sensibilidade de espécies vegetais aos elementos químicos. Em função disso, o estabelecimento de faixas de concentrações normais para o tecido vegetal das plantas não é um processo simples. ${ }^{15}$ Existe grande variação dessas concentrações entre ambientes de mesma região, portanto, os estudos de influência de elementos químicos no tecido vegetal permitem comparar resultados de diferentes experimentos.

As Tabelas 3 e 4 apresentam as concentrações dos elementos químicos durante o ano para cada posição topográfica. A média total dos teores de macronutrientes na liteira, produzida em ordem decrescente na área de platô e baixio foram $\mathrm{Ca}>\mathrm{K}>\mathrm{Mg}>\mathrm{Na}$. Para os micronutrientes, a ordem foi $\mathrm{Al}>\mathrm{Mn}>\mathrm{Fe}>\mathrm{Sr}>\mathrm{Zn}>\mathrm{Cu}>\mathrm{Ba}>$ $\mathrm{Cr}>\mathrm{Ni}>\mathrm{Co}>\mathrm{Cd}$ para o Platô; e $\mathrm{Al}>\mathrm{Mn}>\mathrm{Fe}>\mathrm{Sr}>\mathrm{Zn}>\mathrm{Cu}>$ $\mathrm{Ba}>\mathrm{Cr}>\mathrm{Ni}>\mathrm{Cd}>\mathrm{Co}$ para o baixio.

Houve diferença entre os elementos nas diferentes áreas amostradas. Os valores mais baixos de cálcio e magnésio nas áreas de platô em relação ao baixio, pode ser resultado típico de áreas com solo muito ácido $(\mathrm{pH}<4)$ e com alto teor de argila $(>60 \%),{ }^{16}$ como é o caso desse ambiente que possui um pH de 3,94 e o teor de argila de $86 \% .{ }^{17}$ Isso é explicado, pois solos ácidos de clima úmido, como é o caso do platô, são muito intemperizados, e quanto mais intemperizados o solo, menor a ocorrência de minerais que contêm magnésio e cálcio. ${ }^{18}$

Os valores de $\mathrm{Ca}$ e $\mathrm{Mg}$ mais elevados na liteira do baixio, indicam uma alta eficiência da ciclagem desses nutrientes nesse 
Tabela 3. Concentração dos elementos $\mathrm{Ca}, \mathrm{Mg}$, $\mathrm{Na}$ e $\mathrm{K}$ na liteira para os dois ambientes em estudo (Platô e Baixio) de uma floresta natural na Amazônia central

\begin{tabular}{|c|c|c|c|c|}
\hline & $\mathrm{Ca}$ & $\mathrm{Mg}$ & $\mathrm{Na}$ & $\mathrm{K}$ \\
\hline & \multicolumn{4}{|c|}{ Platô ( $\left.\mathrm{g} \mathrm{kg}^{-1}\right)$} \\
\hline Jan & $17,1 \pm 0,1$ & $5,9 \pm 0,1$ & $3,4 \pm 0,0$ & $9,6 \pm 0,0$ \\
\hline Fev & $14,0 \pm 0,1$ & $5,2 \pm 0,0$ & $2,4 \pm 0,0$ & $5,6 \pm 0,0$ \\
\hline Mar & $13,1 \pm 0,2$ & $4,7 \pm 0,0$ & $1,8 \pm 0,0$ & $4,0 \pm 0,0$ \\
\hline Abr & $12,1 \pm 0,3$ & $5,0 \pm 0,1$ & $1,7 \pm 0,0$ & $5,4 \pm 0,0$ \\
\hline Mai & $11,2 \pm 0,3$ & $4,9 \pm 0,1$ & $2,4 \pm 0,0$ & $4,5 \pm 0,0$ \\
\hline Jun & $13,4 \pm 0,3$ & $5,4 \pm 0,1$ & $2,7 \pm 0,0$ & $4,0 \pm 0,0$ \\
\hline Jul & $12,2 \pm 0,4$ & $5,2 \pm 0,1$ & $2,0 \pm 0,0$ & $4,0 \pm 0,0$ \\
\hline Ago & $12,6 \pm 0,4$ & $6,2 \pm 0,1$ & $2,9 \pm 0,0$ & $5,8 \pm 0,0$ \\
\hline Set & $12,0 \pm 0,3$ & $5,0 \pm 0,1$ & $3,2 \pm 0,0$ & $9,7 \pm 0,0$ \\
\hline Out & $11,0 \pm 0,3$ & $6,1 \pm 0,1$ & $3,7 \pm 0,0$ & $10,6 \pm 0,1$ \\
\hline Nov & $14,3 \pm 0,3$ & $6,1 \pm 0,1$ & $3,1 \pm 0,1$ & $11,6 \pm 0,1$ \\
\hline Dez & $12,1 \pm 0,4$ & $5,9 \pm 0,1$ & $1,5 \pm 0,0$ & $4,0 \pm 0,0$ \\
\hline \multirow[t]{2}{*}{ Média } & $12,9 \pm 1,6$ & $5,5 \pm 0,5$ & $2,6 \pm 0,7$ & $6,6 \pm 2,8$ \\
\hline & \multicolumn{4}{|c|}{ Baixio $\left(\mathrm{g} \mathrm{kg}^{-1}\right)$} \\
\hline Jan & $14,9 \pm 0,2$ & $6,8 \pm 0,1$ & $1,3 \pm 0,0$ & $6,5 \pm 0,0$ \\
\hline Fev & $13,3 \pm 0,2$ & $5,7 \pm 0,1$ & $1,4 \pm 0,0$ & $6,2 \pm 0,0$ \\
\hline Mar & $14,6 \pm 0,3$ & $5,5 \pm 0,1$ & $1,0 \pm 0,0$ & $4,0 \pm 0,0$ \\
\hline Abr & $13,8 \pm 0,2$ & $5,9 \pm 0,1$ & $1,8 \pm 0,0$ & $5,0 \pm 0,0$ \\
\hline Mai & $17,0 \pm 0,4$ & $6,2 \pm 0,2$ & $1,5 \pm 0,0$ & $5,3 \pm 0,0$ \\
\hline Jun & $14,4 \pm 0,3$ & $5,7 \pm 0,2$ & $1,0 \pm 0,0$ & $4,3 \pm 0,0$ \\
\hline Jul & $12,2 \pm 0,2$ & $6,7 \pm 0,1$ & $1,8 \pm 0,0$ & $5,5 \pm 0,0$ \\
\hline Ago & $17,1 \pm 0,3$ & $8,1 \pm 0,2$ & $2,5 \pm 0,0$ & $9,2 \pm 0,1$ \\
\hline Set & $17,9 \pm 0,3$ & $8,2 \pm 0,2$ & $1,7 \pm 0,0$ & $14,3 \pm 0,1$ \\
\hline Out & $21,2 \pm 0,2$ & $11,1 \pm 0,2$ & $2,7 \pm 0,0$ & $16,6 \pm 0,0$ \\
\hline Nov & $12,3 \pm 0,5$ & $8,4 \pm 0,3$ & $1,7 \pm 0,0$ & $15,1 \pm 0,3$ \\
\hline Dez & $12,7 \pm 0,4$ & $7,3 \pm 0,1$ & $1,0 \pm 0,0$ & $11,1 \pm 0,1$ \\
\hline Média & $15,1 \pm 2,6$ & $7,1 \pm 1,6$ & $1,6 \pm 0,5$ & $8,6 \pm 4,4$ \\
\hline
\end{tabular}

ambiente, visto que a quantidade desses elementos é baixa nesses solos, portanto, não possuindo uma dependência desse compartimento. Além disso, os elevados teores de Ca na liteira, em relação a outros macronutrientes, devem-se, em parte, a sua baixa mobilidade interna na planta. ${ }^{19}$ Caldeira et al.,${ }^{2} \mathrm{em}$ seu estudo que avaliou os nutrientes de uma cobertura florestal nativa, encontraram resultados semelhantes para o $\mathrm{Ca}\left(15,31 \mathrm{~g} \mathrm{~kg}^{-1}\right) \mathrm{e}$ valores inferiores para o $\operatorname{Mg}\left(1,48 \mathrm{~g} \mathrm{~kg}^{-1}\right)$.

Os baixos teores de sódio na liteira para ambos os ambientes podem ser, primeiro, pelo fato de as plantas conseguirem completar seu ciclo de vida na sua ausência e, segundo, porque esse nutriente é adsorvido pelos minerais argilosos e sua fixação é mais fraca quando comparado as outras bases trocáveis no solo, ${ }^{9}$ o que pode vir a indicar uma deficiência de Na para a área de estudo. Além disso, as plantas não o absorvem em grandes quantidades e sua fixação no solo é baixa, contribuindo para sua lixiviação para camadas mais profundas. ${ }^{9}$ Rebêlo et al. ${ }^{17}$ também encontraram baixos valores desse nutriente no solo da mesma área de estudo.

Nas concentrações de potássio não houve diferenças expressivas quanto à posição topográfica, entretanto, diferenciou-se na sazonalidade, onde os maiores valores foram observados entre os meses de setembro a novembro, período este de poucas chuvas. Esses resultados indicam que o $\mathrm{K}$ encontrado na liteira se dá em função da época de avaliação, uma vez que possui relação com a precipitação pluviométrica, além disso o potássio ocorre sob a forma solúvel, o que o torna altamente susceptível a lixiviação, ${ }^{20}$ por isso, os maiores valores verificados neste estudo foram no período seco. Caldeira et al. também encontraram menores teores de K na estação chuvosa. ${ }^{2}$

Dentre os micronutrientes, os teores de $\mathrm{Al}, \mathrm{Mn}$ e Fe foram, comparativamente, mais altos que outros elementos. $\mathrm{O}$ teor desses elementos se deve provavelmente ao elevado teor no solo, sendo que a contaminação da liteira com partículas de solo pode ser uma justificativa para explicar a maior concentração. ${ }^{21}$ Rebelo et al.,${ }^{17}$ avaliando solos da mesma área, encontraram altos teores para os três elementos. Esses valores elevados de concentração do Mn e Fe na liteira foram observados em outros estudos..$^{22-24}$

As altas concentrações de Fe no mês de julho podem ser atribuídas ao mês de transição (chuvoso-seco), particularmente, para o ano de 2009, no qual foi o último mês com maior índice pluviométrico antes do período seco. A entrada de ferro parece ser contínua durante o crescimento vegetal, pois não há transferência do metal de uma folha para outra. Segundo Lima e Pedrozo ${ }^{25}$ o processo de obtenção do ferro pelos vegetais envolve a captação do metal do solo pela raiz e o seu transporte até as folhas. Para isso, esse elemento precisa estar solubilizado na solução do solo, para favorecer a absorção pela planta. Portanto, o mês de julho, provavelmente, teve influência para que esse elemento esteja solúvel no solo e absorvido pela raiz, antes da estação seca.

Alguns elementos como $\mathrm{Cd}, \mathrm{Co}, \mathrm{Ni}, \mathrm{Cr}$ e $\mathrm{Ba}$, além de não serem essenciais, ou benéficos às plantas, podem ser extremamente tóxicos em concentrações elevadas, ${ }^{26}$ e por se tratar de um ambiente natural, já era esperado que esses elementos fossem encontrados em menor quantidade neste estudo. Além disso, a disponibilidade desses elementos é dependente de reações no complexo rizosférico envolvendo processos de trocas entre a solução do solo, a planta e microrganismos ${ }^{26}$ e como grande parte desses elementos metálicos apresentam-se na forma total, eles não estão disponíveis para absorção pelas plantas.

Grandes quantidades de nutrientes são transferidas por meio da deposição de liteira, ${ }^{12}$ demonstrando a importância desse processo para a manutenção do equilíbrio nutricional do ecossistema florestal. A contínua ciclagem de nutrientes (no sistema solo-planta-solo), em ecossistemas florestais estabelecidos em solos de baixa fertilidade, como o verificado neste estudo, é fundamental para a manutenção do equilíbrio nutricional do sistema. Se esta camada não for ciclada, nutricional e continuamente, seja por via de deposição de serapilheira, de precipitação úmida ou seca, de intemperização de rochas, de decomposição de árvores e de animais mortos, dentre outros, poderão ocorrer perdas significativas no ecossistema florestal. ${ }^{27}$

A Tabela 5 apresenta as concentrações médias de macronutrientes ao longo do ano das frações de liteira (folha, material lenhoso e material reprodutivo) em duas estações do ano (chuvosa e seca).

De forma geral, o conteúdo de cálcio teve maior concentração no material lenhoso entre as frações da liteira para as duas áreas de estudo e nas diferentes estações. Segundo Selle, ${ }^{28}$ a copa armazena em média $24 \%$ do total dos nutrientes da árvore e é na casca e nos galhos que estão as maiores quantidades de $\mathrm{Ca}$, por ser um elemento de baixa mobilidade no tecido vegetal, ficando mais concentrado nas partes lignificadas.

O magnésio teve sua maior concentração na fração foliar. $\mathrm{O}$ maior teor de $\mathrm{Mg}$ nas folhas é atribuído, provavelmente, por esse elemento fazer parte da clorofila na proporção de $2,7 \%$ desta, sendo assim mais abundante nestes tecidos. ${ }^{29}$ Teores mais elevados de $\mathrm{Mg}$ nas folhas também foram observados por Espig et al. ${ }^{30} \mathrm{e}$ podem ser explicados pelo fato de que, durante a decomposição da liteira, o Mg não é facilmente lixiviado, ao contrário dos carboidratos solúveis, o 
Tabela 4. Concentração dos elementos Al, Ba, Co, Cr, Cu, Mn, Fe, Ni, Sr, Zn e Cd na liteira para os dois ambientes em estudo (Platô e Baixio) de uma floresta natural na Amazônia central

\begin{tabular}{|c|c|c|c|c|c|c|c|c|c|c|c|}
\hline & $\mathrm{Al}$ & $\mathrm{Ba}$ & $\mathrm{Co}$ & $\mathrm{Cr}$ & $\mathrm{Cu}$ & $\mathrm{Mn}$ & $\mathrm{Fe}$ & $\mathrm{Ni}$ & $\mathrm{Sr}$ & $\mathrm{Zn}$ & $\mathrm{Cd}$ \\
\hline & \multicolumn{11}{|c|}{ Platô (mg kg ${ }^{-1}$ ) } \\
\hline Jan & $3134,2 \pm 14,1$ & $6,9 \pm 0,2$ & $0,8 \pm 0,0$ & $3,7 \pm 0,1$ & $21,1 \pm 0,3$ & $424 \pm 1,6$ & $251,8 \pm 1,2$ & $2,8 \pm 0,1$ & $158 \pm 0,8$ & $48,7 \pm 0,1$ & $0,8 \pm 0,0$ \\
\hline Fev & $1350,3 \pm 5,6$ & $4,6 \pm 0,1$ & $0,1 \pm 0,0$ & $2,7 \pm 0,1$ & $19,4 \pm 0,1$ & $384,1 \pm 1,2$ & $142,4 \pm 0,7$ & $2,9 \pm 0,1$ & $127,1 \pm 1,0$ & $67,3 \pm 0,1$ & $0,2 \pm 0,0$ \\
\hline Mar & $2406,6 \pm 18,5$ & $4,0 \pm 0,1$ & $0,1 \pm 0,0$ & $2,5 \pm 0,1$ & $18,6 \pm 0,2$ & $381,6 \pm 1,1$ & $143,5 \pm 0,3$ & $2 \pm 0,1$ & $113,3 \pm 0,9$ & $44,6 \pm 0,1$ & $<\mathrm{LD}$ \\
\hline Abr & $2979 \pm 26,6$ & $5,2 \pm 0,2$ & $0,1 \pm 0,1$ & $2,2 \pm 0,1$ & $19,3 \pm 0,1$ & $419,9 \pm 1,6$ & $206 \pm 0,9$ & $2,6 \pm 0,0$ & $108,3 \pm 1,6$ & $54,1 \pm 1,0$ & $<\mathrm{LD}$ \\
\hline Mai & $2272,5 \pm 14,6$ & $3,5 \pm 0,1$ & $0,1 \pm 0,1$ & $2,5 \pm 0,1$ & $18,2 \pm 0,1$ & $360,3 \pm 0,9$ & $198,7 \pm 0,7$ & $2,4 \pm 0,1$ & $105,7 \pm 1,2$ & $49 \pm 0,2$ & $<\mathrm{LD}$ \\
\hline Jun & $2756,8 \pm 14,0$ & $3,8 \pm 0,1$ & $0,1 \pm 0,0$ & $2,5 \pm 0,1$ & $20,0 \pm 0,2$ & $496,9 \pm 1,1$ & $194,6 \pm 0,5$ & $3,9 \pm 0,1$ & $117,8 \pm 1,2$ & $54 \pm 0,2$ & $<\mathrm{LD}$ \\
\hline Jul & $2670,7 \pm 24,7$ & $5,2 \pm 0,3$ & $0,5 \pm 0,1$ & $3,7 \pm 0,1$ & $18,7 \pm 0,2$ & $411,1 \pm 2,2$ & $257,9 \pm 1,4$ & $2,9 \pm 0,1$ & $110,6 \pm 1,9$ & $50,6 \pm 0,4$ & $0,5 \pm 0,0$ \\
\hline Ago & $4536,7 \pm 31,2$ & $3,7 \pm 0,1$ & $0,1 \pm 0,1$ & $3,0 \pm 0,1$ & $21 \pm 0,2$ & $441,3 \pm 2,2$ & $168,9 \pm 1,2$ & $2,5 \pm 0,1$ & $117,9 \pm 2,1$ & $60,1 \pm 0,2$ & $0,1 \pm 0,0$ \\
\hline Set & $3720,8 \pm 37,6$ & $5,6 \pm 0,1$ & $0,2 \pm 0,0$ & $2,8 \pm 0,1$ & $19,2 \pm 0,3$ & $442,1 \pm 2,6$ & $342,5 \pm 2,5$ & $2,2 \pm 0,1$ & $112,4 \pm 1,9$ & $50,4 \pm 0,2$ & $<\mathrm{LD}$ \\
\hline Out & $3233,6 \pm 10,4$ & $6,5 \pm 0,1$ & $0,1 \pm 0,1$ & $2,8 \pm 0,1$ & $21,7 \pm 0,4$ & $419,7 \pm 2,8$ & $170,5 \pm 0,9$ & $2,5 \pm 0,0$ & $121,3 \pm 2,2$ & $68,1 \pm 0,2$ & $<\mathrm{LD}$ \\
\hline Nov & $2731,2 \pm 13,4$ & $6,1 \pm 0,1$ & $0,1 \pm 0,1$ & $2,4 \pm 0,1$ & $19,8 \pm 0,3$ & $399,1 \pm 2,0$ & $197,5 \pm 1,0$ & $2,5 \pm 0,1$ & $128,1 \pm 2,4$ & $44,4 \pm 0,2$ & $<\mathrm{LD}$ \\
\hline Dez & $3150,4 \pm 16,2$ & $4,4 \pm 0,2$ & $0,2 \pm 0,0$ & $3,5 \pm 0,1$ & $20,2 \pm 0,3$ & $388,6 \pm 1,8$ & $249,7 \pm 1,0$ & $2,4 \pm 0,1$ & $121,5 \pm 3,1$ & $52,5 \pm 0,4$ & $<\mathrm{LD}$ \\
\hline \multirow[t]{2}{*}{ Média } & $2911,9 \pm 2893,4$ & $5 \pm 1,1$ & $0,2 \pm 0,2$ & $2,9 \pm 0,5$ & $19,8 \pm 1,0$ & $414,1 \pm 34,5$ & $210,3 \pm 54,7$ & $2,6 \pm 0,5$ & $120,2 \pm 13,2$ & $53,6 \pm 7,5$ & $0,1 \pm 0,3$ \\
\hline & \multicolumn{11}{|c|}{ Baixio (mg kg-1) } \\
\hline Jan & $437,1 \pm 1,2$ & $10,8 \pm 0,1$ & $0,3 \pm 0,0$ & $3 \pm 0,1$ & $10,2 \pm 0,1$ & $307,3 \pm 0,7$ & $149,2 \pm 0,6$ & $1,4 \pm 0,1$ & $143,1 \pm 0,9$ & $51,3 \pm 0,2$ & $0,5 \pm 0,0$ \\
\hline Fev & $451,1 \pm 1,3$ & $8,2 \pm 0,1$ & $0,1 \pm 0,0$ & $2,5 \pm 0,1$ & $9,1 \pm 0,1$ & $309,8 \pm 1,5$ & $118,7 \pm 0,4$ & $1,6 \pm 0,0$ & $147,9 \pm 1,1$ & $50 \pm 0,2$ & $0,2 \pm 0,0$ \\
\hline Mar & $303,9 \pm 1,1$ & $9,1 \pm 0,2$ & $0,1 \pm 0,0$ & $2,9 \pm 0,0$ & $9,5 \pm 0,2$ & $262,7 \pm 0,8$ & $133,1 \pm 0,2$ & $0,8 \pm 0,1$ & $148,8 \pm 1,2$ & $55,8 \pm 0,2$ & $0,2 \pm 0,0$ \\
\hline Abr & $378 \pm 0,9$ & $8,4 \pm 0,1$ & $0,1 \pm 0,0$ & $2,7 \pm 0,1$ & $11,7 \pm 0,1$ & $444,8 \pm 1,4$ & $150,6 \pm 0,4$ & $1,1 \pm 0,1$ & $137,7 \pm 0,5$ & $52,3 \pm 0,2$ & $0,1 \pm 0,0$ \\
\hline Mai & $338,2 \pm 1,5$ & $8,9 \pm 0,2$ & $0,1 \pm 0,0$ & $3,2 \pm 0,0$ & $11,9 \pm 0,2$ & $380 \pm 1,0$ & $183,5 \pm 0,6$ & $1,2 \pm 0,1$ & $173,2 \pm 2,9$ & $56,2 \pm 0,2$ & $0,2 \pm 0,0$ \\
\hline Jun & $307,5 \pm 1,6$ & $10,8 \pm 0,2$ & $0,2 \pm 0,0$ & $4,3 \pm 0,1$ & $10,9 \pm 0,2$ & $341 \pm 1,4$ & $290,4 \pm 0,8$ & $1,8 \pm 0,0$ & $135,3 \pm 1,8$ & $74,3 \pm 0,2$ & $0,2 \pm 0,0$ \\
\hline Jul & $288,9 \pm 2,3$ & $9,2 \pm 0,4$ & $1,1 \pm 0,1$ & $4,1 \pm 0,3$ & $12 \pm 0,3$ & $401,8 \pm 2,5$ & $237,3 \pm 1,3$ & $2,1 \pm 0,1$ & $120,2 \pm 1,4$ & $56,1 \pm 0,3$ & $1,5 \pm 0,1$ \\
\hline Ago & $393,9 \pm 1,5$ & $9,9 \pm 0,2$ & $0,1 \pm 0,0$ & $3,3 \pm 0,1$ & $9,8 \pm 0,3$ & $409,1 \pm 1,5$ & $146,6 \pm 0,9$ & $1 \pm 0,1$ & $149,9 \pm 1,5$ & $73,3 \pm 0,2$ & $0,2 \pm 0,0$ \\
\hline Set & $424 \pm 1,1$ & $6,3 \pm 0,2$ & $0,1 \pm 0,0$ & $2,2 \pm 0,0$ & $11 \pm 0,1$ & $352,1 \pm 0,8$ & $153 \pm 0,5$ & $0,9 \pm 0,1$ & $134,5 \pm 1,9$ & $71,7 \pm 0,4$ & $0,1 \pm 0,0$ \\
\hline Out & $283,8 \pm 1,7$ & $13,2 \pm 0,2$ & $0,2 \pm 0,1$ & $2,8 \pm 0,0$ & $12,5 \pm 0,2$ & $335,5 \pm 1,5$ & $141 \pm 0,6$ & $1 \pm 0,1$ & $184,6 \pm 1,5$ & $93 \pm 0,5$ & $0,2 \pm 0,0$ \\
\hline Nov & $277 \pm 1,7$ & $8,7 \pm 0,2$ & $0,1 \pm 0,1$ & $2,2 \pm 0,1$ & $10,4 \pm 0,1$ & $276,1 \pm 2,1$ & $116,9 \pm 1,1$ & $0,9 \pm 0,1$ & $133,2 \pm 3,5$ & $56,7 \pm 0,3$ & $0,1 \pm 0,0$ \\
\hline Dez & $267,9 \pm 1,0$ & $7 \pm 0,2$ & $0,1 \pm 0,0$ & $2,8 \pm 0,1$ & $12,9 \pm 0,2$ & $237,8 \pm 1,0$ & $111,5 \pm 0,7$ & $1 \pm 0,0$ & $121,9 \pm 2,2$ & $61 \pm 0,5$ & $0,1 \pm 0,0$ \\
\hline Média & $345,9 \pm 338,3$ & $9,2 \pm 1,8$ & $0,2 \pm 0,3$ & $3 \pm 0,6$ & $11 \pm 1,2$ & $338,2 \pm 60,4$ & $161 \pm 50,8$ & $1,2 \pm 0,4$ & $144,2 \pm 18,2$ & $62,7 \pm 12,3$ & $0,3 \pm 0,4$ \\
\hline
\end{tabular}

Tabela 5. Valores médios da concentração sazonal dos macronutrientes nas frações folha, material lenhoso e material reprodutivo nas estações seca e chuvosa em floresta natural na Amazônia Central

\begin{tabular}{|c|c|c|c|c|c|c|c|c|}
\hline & \multicolumn{4}{|c|}{ Estação Chuvosa } & \multicolumn{4}{|c|}{ Estação Seca } \\
\hline & $\mathrm{Ca}$ & $\mathrm{Mg}$ & $\mathrm{K}$ & $\mathrm{Na}$ & $\mathrm{Ca}$ & $\mathrm{Mg}$ & $\mathrm{K}$ & $\mathrm{Na}$ \\
\hline & \multicolumn{8}{|c|}{ Platô ( $\left.\mathrm{g} \mathrm{kg}^{-1}\right)$} \\
\hline Folha & $3,6 \pm 0,1$ & $1,9 \pm 0,0$ & $1,3 \pm 0,0$ & $0,9 \pm 0,0$ & $3,9 \pm 0,1$ & $1,9 \pm 0,0$ & $1,4 \pm 0,0$ & $1,3 \pm 0,0$ \\
\hline M. L. & $7,6 \pm 0,1$ & $1,7 \pm 0,0$ & $1,4 \pm 0,0$ & $0,6 \pm 0,0$ & $6,2 \pm 0,1$ & $1,6 \pm 0,0$ & $1,3 \pm, 0$ & $0,5 \pm 0,0$ \\
\hline \multirow[t]{2}{*}{ M. R. } & $2,2 \pm 0,1$ & $1,5 \pm 0,0$ & $2,8 \pm 0,0$ & $0,8 \pm 0,0$ & $3,0 \pm 0,1$ & $2,2 \pm 0,0$ & $4,9 \pm 0,0$ & $0,9 \pm 0,0$ \\
\hline & \multicolumn{8}{|c|}{ Baixio $\left(\mathrm{g} \mathrm{kg}^{-1}\right)$} \\
\hline Folha & $3,6 \pm 0,1$ & $2,2 \pm 0,0$ & $1,5 \pm 0,0$ & $0,6 \pm 0,0$ & $5,0 \pm 0,1$ & $2,9 \pm 0,1$ & $2,2 \pm 0,0$ & $0,8 \pm 0,1$ \\
\hline M. L. & $7,8 \pm 0,1$ & $1,6 \pm 0,0$ & $1,1 \pm 0,1$ & $0,3 \pm 0,0$ & $7,0 \pm 0,1$ & $2,5 \pm 0,1$ & $3,1 \pm 0,0$ & $0,5 \pm 0,0$ \\
\hline M. R. & $3,3 \pm 0,1$ & $2,1 \pm 0,0$ & $2,6 \pm 0,0$ & $0,4 \pm 0,0$ & $3,5 \pm 0,1$ & $2,9 \pm 0,0$ & $6,6 \pm 0,0$ & $0,6 \pm 0,0$ \\
\hline
\end{tabular}

Em que: M. L. = Material Lenhoso; M. R. = Material Reprodutivo.

que contribui para elevar os teores desses nutrientes por unidade de massa de liteira foliar. ${ }^{31}$

O potássio, no entanto, obteve maiores concentrações médias na fração de material reprodutivo. $\mathrm{O}$ maior teor de $\mathrm{K}$ nos órgãos reprodutivos, e posteriormente nas folhas recém depositadas se deve ao fato de que essas frações apresentam menor grau de decomposição, sendo que há uma maior dificuldade de lixiviação do $\mathrm{K}$ desses tecidos. ${ }^{23}$ Além disso, as concentrações maiores do $\mathrm{K}$ nas estruturas reprodutivas, provavelmente, estão relacionadas com a alta mobilidade desse elemento no floema para que, prontamente, seja redistribuído para os órgãos novos em crescimento, sendo uma de suas funções proteger a planta contra doenças, além de auxiliar na manutenção dos frutos. ${ }^{32}$ Godinho et al. ${ }^{33}$ e Holanda et al. ${ }^{34}$ também encontraram maiores teores de $\mathrm{K}$ no material reprodutivo. 
A Tabela 6 apresenta as concentrações médias de micronutrientes ao longo do ano das frações de liteira (folha, material lenhoso e material reprodutivo) em duas estações do ano (chuvosa e seca).

De forma geral, o Al foi o elemento de maior predominância em todas as partes da planta, principalmente na estrutura foliar. Os maiores valores verificados na folha estão nas áreas de platô. Isso pode ser explicado pela hiper acumulação desse elemento em angiospermas, uma vez que esta família tem uma grande representatividade nessa topografia. ${ }^{35}$ As concentrações significativamente mais altas de manganês e ferro foram, ligeiramente, maior no material lenhoso para as diferentes áreas e estações, o que pode indicar que esses elementos participam mais da parte estrutural da planta. Schumacher et al.,$^{36}$ avaliando os nutrientes em uma floresta estacional decidual, também encontraram maiores valores de $\mathrm{Fe}$ e $\mathrm{Mn}$ nos galhos.

Os demais elementos traço (cobre, cromo e níquel) foram encontrados em baixíssimas concentrações em todas as frações da liteira. De acordo com Pedrozo, ${ }^{37}$ o cobre é requerido em pequenas quantidades para o crescimento normal da planta, 5 a $20 \mathrm{mg} \mathrm{kg}^{-1}$, participando apenas no processo de resistência a doenças. Dependendo da espécie da planta, do órgão da planta, do estágio de seu desenvolvimento e do suprimento de nitrogênio, essas faixas podem ser maiores. Nos vegetais, a maior parte do cromo é retida nas raízes e somente uma pequena parcela é transportada para as partes superiores das plantas, sendo improvável a bioacumulação do cromo proveniente do solo nessas partes. De acordo com Merian, ${ }^{38} \mathrm{a}$ concentração de níquel em plantas pode variar entre 0,05 a 5,0 mg kg-1 (peso seco), para este trabalho a concentração variou de 0,25 a $0,97 \mathrm{mg} \mathrm{kg}^{-1}$ entre as frações analisadas.

O fluxo de nutrientes da liteira para o solo determina importantes processos nos ecossistemas florestais como a decomposição e a mineralização. ${ }^{39}$ Esses processos são controlados pela quantidade de liteira produzida e concentração de nutrientes nela contida. ${ }^{40}$ A quantidade dos nutrientes transferidos ao solo via deposição de liteira são muito variáveis entre as florestas tropicais e dependem das características funcionais de cada elemento no metabolismo das plantas, da presença ou ausência de mecanismos de conservação de nutrientes, das condições edafoclimáticas, das exigências nutricionais das espécies, da parte da planta considerada, da fenologia, da época do ano, da composição florística, do estádio sucessional e da metodologia empregada na avaliação. ${ }^{41,42}$

De forma geral, para todos os elementos, encontrou-se maiores valores na estação seca, principalmente no período de junho a agosto, indicando que o fator sazonalidade teve influência direta no retorno desses elementos a partir da liteira. Esse fato se deve à maior produção de liteira nesse período, com base nos dados de Conceição et al. ${ }^{12}$ Uma das características da floresta tropical e subtropical úmida é a produção de liteira, com máximos valores na estação seca. ${ }^{43}$ Golley ${ }^{44}$ menciona que a produção de liteira em regiões tropicais e subtropicais ocorre na transição entre a estação seca e a chuvosa.

Com os dados da liteira produzida e a sua concentração de nutrientes, ${ }^{12}$ foi possível calcular a quantidade de nutrientes que retorna ao solo. Nas Tabelas 7 e 8 observa-se a transferência anual dos elementos por meio da liteira ao solo ao longo do ano.

Os resultados permitem concluir que avaliando os elementos na mesma posição topográfica entre os meses do ano, houve diferença significativa a $5 \%$ de probabilidade segundo o teste Tukey para o $\mathrm{Ca}$, sendo ele mais representativo tanto para o platô quanto para o baixio. Esse resultado pode estar relacionado ao fato de o Ca ser um elemento estruturante e apresentar-se com baixíssima mobilidade no ciclo bioquímico. ${ }^{34} \mathrm{O}$ menor retorno dos demais elementos ao solo pode ser atribuído à característica de alta mobilidade no solo, principalmente do Mg e K. Além disso, observa-se que as maiores concentrações desses nutrientes foram encontradas em solos do baixio, isso pode estar relacionado ao processo de lixiviação, que carrega nutrientes das áreas mais altas para as mais baixas através da água.

Entretanto, quando comparou-se o mesmo elemento entre platô e baixio, apenas o sódio obteve diferença significativa, sendo encontrado em menor quantidade na área de baixio. Esse resultado pode ser explicado pelo fato de que sua adsorção é feita pelos minerais

Tabela 6. Valores da concentração sazonal dos elementos metálicos nas frações folha, material lenhoso e material reprodutivo nas estações seca e chuvosa em floresta natural na Amazônia Central

\begin{tabular}{|c|c|c|c|c|c|c|c|c|c|c|c|}
\hline \multicolumn{12}{|c|}{ Estação Chuvosa } \\
\hline & $\mathrm{Al}$ & $\mathrm{Ba}$ & Co & $\mathrm{Cr}$ & $\mathrm{Cu}$ & $\mathrm{Fe}$ & $\mathrm{Mn}$ & $\mathrm{Ni}$ & $\mathrm{Sr}$ & $\mathrm{Zn}$ & $\mathrm{Cd}$ \\
\hline & \multicolumn{11}{|c|}{ Platô (mg kg-1) } \\
\hline Folha & $1272,8 \pm 9,1$ & $1,2 \pm 0,0$ & $<\mathrm{LD}$ & $0,7 \pm 0,0$ & $4,2 \pm 0,0$ & $53,0 \pm 0,2$ & $119,8 \pm 0,4$ & $0,9 \pm 0,0$ & $36,0 \pm 0,4$ & $14,5 \pm 0,0$ & $<\mathrm{LD}$ \\
\hline M. L. & $1007,6 \pm 5,6$ & $2,8 \pm 0,1$ & $<\mathrm{LD}$ & $1,0 \pm 0,0$ & $6,9 \pm 0,1$ & $92,1 \pm 0,4$ & $229,9 \pm 0,7$ & $1,0 \pm 0,0$ & $66,6 \pm 0,5$ & $22,7 \pm 0,2$ & $<\mathrm{LD}$ \\
\hline \multirow[t]{2}{*}{ M. R. } & $202,8 \pm 0,8$ & $0,7 \pm 0,0$ & $<\mathrm{LD}$ & $0,9 \pm 0,0$ & $8,3 \pm 0,1$ & $44,4 \pm 0,1$ & $61,4 \pm 0,1$ & $0,9 \pm 0,0$ & $19,1 \pm 0,1$ & $15,7 \pm 0,0$ & $0,1 \pm 0,0$ \\
\hline & \multicolumn{11}{|c|}{ Baixio $\left(\mathrm{mg} \mathrm{kg}^{-1}\right)$} \\
\hline Folha & $158,1 \pm 0,5$ & $2,4 \pm 0,0$ & $<\mathrm{LD}$ & $0,8 \pm 0,0$ & $2,1 \pm 0,1$ & $42,8 \pm 0,1$ & $133,0 \pm 0,4$ & $0,2 \pm 0,0$ & $38,2 \pm 0,4$ & $11,8 \pm 0,1$ & $<\mathrm{LD}$ \\
\hline M. L. & $85,5 \pm 0,4$ & $4,8 \pm 0,1$ & $<\mathrm{LD}$ & $0,9 \pm 0,0$ & $2,9 \pm 0,1$ & $49,7 \pm 0,2$ & $109,0 \pm 0,4$ & $0,3 \pm 0,0$ & $75,5 \pm 0,7$ & $22,3 \pm 0,1$ & $0,1 \pm 0,0$ \\
\hline M. R. & $125,7 \pm 0,5$ & $2,2 \pm 0,0$ & $0,1 \pm 0,0$ & $1,4 \pm 0,0$ & $5,5 \pm 0,0$ & $78,4 \pm 0,2$ & $98,9 \pm 0,3$ & $0,7 \pm 0,0$ & $34,0 \pm 0,3$ & $22,6 \pm 0,1$ & $0,1 \pm 0,0$ \\
\hline \multicolumn{12}{|c|}{ Estação Seca } \\
\hline & \multicolumn{11}{|c|}{ Platô (mg kg-1) } \\
\hline Folha & $1743,4 \pm 8,8$ & $1,2 \pm 0,0$ & $<\mathrm{LD}$ & $0,8 \pm 0,0$ & $3,7 \pm 0,1$ & $59,1 \pm 0,3$ & $119,5 \pm 0,5$ & $0,8 \pm 0,0$ & $31,4 \pm 0,5$ & $11,5 \pm 0,0$ & $<\mathrm{LD}$ \\
\hline M. L. & $878,7 \pm 7,4$ & $2,2 \pm 0,1$ & $0,1 \pm 0,0$ & $1,1 \pm 0,0$ & $6,5 \pm 0,1$ & $95,0 \pm 0,4$ & $206,9 \pm 1,2$ & $0,7 \pm 0,0$ & $57,8 \pm 1,2$ & $22,7 \pm 0,1$ & $<\mathrm{LD}$ \\
\hline \multirow[t]{2}{*}{ M. R. } & $718,5 \pm 6,0$ & $1,8 \pm 0,0$ & $0,1 \pm 0,0$ & $1,1 \pm 0,0$ & $9,9 \pm 0,1$ & $77,1 \pm 0,6$ & $90,7 \pm 0,5$ & $0,9 \pm 0,0$ & $29,4 \pm 0,5$ & $20,1 \pm 0,1$ & $0,1 \pm, 0$ \\
\hline & \multicolumn{11}{|c|}{ Baixio (mg kg-1) } \\
\hline Folha & $146,5 \pm 0,6$ & $2,7 \pm 0,1$ & $0,2 \pm 0,0$ & $0,9 \pm 0,1$ & $2,7 \pm 0,1$ & $46,1 \pm 0,2$ & $126,8 \pm 0,5$ & $0,4 \pm 0,0$ & $43,5 \pm 0,6$ & $16,1 \pm 0,1$ & $0,2 \pm 0,0$ \\
\hline M. L. & $105,8 \pm 0,4$ & $4,1 \pm 0,1$ & $0,1 \pm 0,0$ & $0,9 \pm 0,0$ & $3,7 \pm 0,0$ & $45,1 \pm 0,2$ & $117,9 \pm 0,4$ & $0,2 \pm 0,0$ & $63,8 \pm 0,9$ & $29,3 \pm 0,2$ & $0,1 \pm 0,0$ \\
\hline M. R. & $70,2 \pm 0,5$ & $2,2 \pm 0,1$ & $0,1 \pm 0,0$ & $1,1 \pm 0,0$ & $5,0 \pm 0,1$ & $59,9 \pm 0,5$ & $90,7 \pm 0,5$ & $0,5 \pm 0,0$ & $33,4 \pm 0,5$ & $23,2 \pm 0,1$ & $0,1 \pm 0,0$ \\
\hline
\end{tabular}

Em que: M. L. = Material Lenhoso; M. R. = Material Reprodutivo. 
Tabela 7. Conteúdo de macronutrientes que retornam ao solo através da liteira em uma área de floresta natural na Amazônia Central

\begin{tabular}{|c|c|c|c|c|c|c|c|c|}
\hline \multirow{2}{*}{ Mês } & \multicolumn{4}{|c|}{ Platô (kg ha-1) } & \multicolumn{4}{|c|}{ Baixio $\left(\mathrm{kg} \mathrm{ha}^{-1}\right)$} \\
\hline & $\mathrm{Ca}$ & $\mathrm{Mg}$ & $\mathrm{Na}$ & $\mathrm{K}$ & $\mathrm{Ca}$ & $\mathrm{Mg}$ & $\mathrm{Na}$ & $\mathrm{K}$ \\
\hline Jan & $7,0 \pm 1,3$ & $2,4 \pm 0,5$ & $1,4 \pm 0,3$ & $3,9 \pm 0,7$ & $7,0 \pm 1,6$ & $3,2 \pm 0,7$ & $0,6 \pm 0,1$ & $3,0 \pm 0,7$ \\
\hline Fev & $5,9 \pm 1,9$ & $2,2 \pm 0,7$ & $1,0 \pm 0,3$ & $2,3 \pm 0,8$ & $4,8 \pm 0,7$ & $2,0 \pm 0,3$ & $0,5 \pm 0,1$ & $2,2 \pm 0,3$ \\
\hline Mar & $8,6 \pm 1,5$ & $3,1 \pm 0,5$ & $1,2 \pm 0,2$ & $2,6 \pm 0,5$ & $6,6 \pm 1,5$ & $2,5 \pm 0,6$ & $0,4 \pm 0,1$ & $1,8 \pm 0,4$ \\
\hline Abr & $5,7 \pm 1,4$ & $2,3 \pm 0,6$ & $0,8 \pm 0,2$ & $2,5 \pm 0,6$ & $6,4 \pm 0,6$ & $2,7 \pm 0,3$ & $0,8 \pm 0,1$ & $2,3 \pm 0,2$ \\
\hline Maio & $7,8 \pm 1,9$ & $3,4 \pm 0,9$ & $1,7 \pm 0,4$ & $3,1 \pm 0,8$ & $9,4 \pm 1,4$ & $3,4 \pm 0,5$ & $0,8 \pm 0,1$ & $2,9 \pm 0,4$ \\
\hline Jun & $12,4 \pm 1,7$ & $5,0 \pm 0,7$ & $2,5 \pm 0,3$ & $3,7 \pm 0,5$ & $12,4 \pm 1,7$ & $4,9 \pm 0,7$ & $0,8 \pm 0,1$ & $3,7 \pm 0,5$ \\
\hline Jul & $11,8 \pm 1,9$ & $5,0 \pm 0,8$ & $1,9 \pm 0,3$ & $3,9 \pm 0,6$ & $10,0 \pm 0,7$ & $5,5 \pm 0,4$ & $1,4 \pm 0,1$ & $4,5 \pm 0,3$ \\
\hline Ago & $15,9 \pm 4,2$ & $7,9 \pm 2,1$ & $3,6 \pm 1,0$ & $7,3 \pm 1,9$ & $18,2 \pm 3,9$ & $8,7 \pm 1,9$ & $2,7 \pm 0,6$ & $9,8 \pm 2,1$ \\
\hline Set & $11,5 \pm 1,7$ & $4,8 \pm 0,7$ & $3,1 \pm 0,5$ & $9,3 \pm 1,4$ & $17,1 \pm 3,6$ & $7,8 \pm 1,7$ & $1,6 \pm 0,3$ & $13,6 \pm 2,9$ \\
\hline Out & $9,0 \pm 2,6$ & $5,0 \pm 1,4$ & $3,1 \pm 0,9$ & $8,7 \pm 2,5$ & $15,8 \pm 2,2$ & $8,3 \pm 1,1$ & $2,0 \pm 0,3$ & $12,4 \pm 1,7$ \\
\hline Nov & $6,6 \pm 1,1$ & $2,8 \pm 0,5$ & $1,4 \pm 0,2$ & $5,4 \pm 0,9$ & $5,1 \pm 0,3$ & $3,5 \pm 0,2$ & $0,7 \pm 0,0$ & $6,3 \pm 0,3$ \\
\hline Dez & $5,4 \pm 1,1$ & $2,7 \pm 0,5$ & $0,7 \pm 0,1$ & $1,8 \pm 0,4$ & $5,9 \pm 1,1$ & $3,4 \pm 0,7$ & $0,5 \pm 0,1$ & $5,2 \pm 1,0$ \\
\hline Total & 107,7 & 46,7 & 22,3 & 54,7 & 118,7 & 56,0 & 13,0 & 67,8 \\
\hline Média & $8,97 \mathrm{aA}$ & $3,89 \mathrm{cdA}$ & $1,86 \mathrm{cA}$ & $4,56 \mathrm{bdA}$ & $9,90 \mathrm{aA}$ & $4,67 \mathrm{cdA}$ & $1,08 \mathrm{cB}$ & $5,65 \mathrm{bdA}$ \\
\hline
\end{tabular}

Cada valor mensal corresponde à média de 3 repetições. Para a média mensal, os valores seguidos da mesma letra minúscula para os metais dentro da mesma área; e maiúsculas para o mesmo metal entre áreas diferentes, não diferem entre si ao nível de $5 \%$ pelo teste de Tukey.

argilosos, que é o caso dos solos na área de platô. ${ }^{9}$ Além disso, esse elemento obteve os maiores valores nas áreas de platô e baixas quantidades no solo do baixio, o que explica o menor retorno desse elemento por meio da liteira. ${ }^{17}$

Há uma série de fatores abióticos e bióticos que influenciam e interferem na quantidade de nutrientes que retornam ao solo via liteira em diferentes ecossistemas, e isso é muito relativo, conforme pode ser verificado no trabalho realizado por Hayashi, ${ }^{40}$ em um estudo realizado numa floresta primária no município de Capitão Poço PA, no qual encontrou valores totais durante o ano $\left(\mathrm{kg} \mathrm{ha}^{-1}\right)$ de 23,8 para $\mathrm{Ca}, 17,4$ para $\mathrm{Mg}$ e 11,7 para $\mathrm{K}$. Brun et al., em uma floresta estacional decidual madura, encontraram valores $\left(\mathrm{kg} \mathrm{ha}^{-1} \mathrm{ano}^{-1}\right)$ de 175,0 para Ca, 24,6 para Mg e 81,7 para K. Essas diferenças podem ser atribuídas à diversidade florística dos locais que exercem grande influência nos resultados. ${ }^{41}$

A Tabela 8 representa o retorno dos micronutrientes do solo via liteira. Não serão apresentados valores de $\mathrm{Co}$, $\mathrm{Ni}$ e $\mathrm{Cd}$, uma vez que esses elementos se encontraram naturalmente em baixas concentrações $\left(<10^{-4}\right)$.

A partir dos resultados obtidos pela análise de variância, observa-se que dentro de uma mesma área nos diferentes meses do ano, o alumínio diferiu significativamente a um nível de $5 \%$ de probabilidade, sendo esse o micronutriente de maior retorno ao solo via liteira. Quando se comparou o mesmo elemento entre diferentes áreas, apenas o $\mathrm{Al}$ e $\mathrm{Zn}$ diferiram significativamente, sendo sempre os nutrientes de maiores retorno na área de platô, fato esse relacionado

Tabela 8. Conteúdo de micronutrientes que retornam ao solo através da liteira em uma área de floresta natural na Amazônia Central

\begin{tabular}{|c|c|c|c|c|c|c|c|c|c|c|c|c|c|c|}
\hline \multirow{2}{*}{ Mês } & \multicolumn{7}{|c|}{ Platô (kg ha-1) } & \multicolumn{7}{|c|}{ Baixio $\left(\mathrm{kg} \mathrm{ha}^{-1}\right)$} \\
\hline & $\mathrm{Al}$ & $\mathrm{Ba}$ & $\mathrm{Cu}$ & $\mathrm{Fe}$ & $\mathrm{Mn}$ & $\mathrm{Sr}$ & $\mathrm{Zn}$ & $\mathrm{Al}$ & $\mathrm{Ba}$ & $\mathrm{Cu}$ & $\mathrm{Fe}$ & $\mathrm{Mn}$ & $\mathrm{Sr}$ & $\mathrm{Zn}$ \\
\hline Jan & $1,3 \pm 0,2$ & $<\mathrm{LD}$ & $<\mathrm{LD}$ & $0,1 \pm 0,0$ & $0,2 \pm 0,0$ & $0,1 \pm 0,0$ & $0,1 \pm 0,0$ & $0,2 \pm 0,0$ & $<\mathrm{LD}$ & $<\mathrm{LD}$ & $0,1 \pm 0,0$ & $0,1 \pm 0,0$ & $0,1 \pm 0,0$ & $<\mathrm{LD}$ \\
\hline Fev & $0,6 \pm 0,2$ & $<\mathrm{LD}$ & $<\mathrm{LD}$ & $0,1 \pm 0,0$ & $0,2 \pm 0,0$ & $0,1 \pm 0,0$ & $0,1 \pm 0,0$ & $0,2 \pm 0,0$ & $<\mathrm{LD}$ & $<\mathrm{LD}$ & $0,0 \pm 0,0$ & $0,1 \pm 0,0$ & $0,1 \pm 0,0$ & $<\mathrm{LD}$ \\
\hline Mar & $1,4 \pm 0,3$ & $<\mathrm{LD}$ & $<\mathrm{LD}$ & $0,1 \pm 0,0$ & $0,2 \pm 0,0$ & $0,1 \pm 0,0$ & $0,1 \pm 0,0$ & $0,1 \pm 0,0$ & $<\mathrm{LD}$ & $<\mathrm{LD}$ & $0,1 \pm 0,0$ & $0,1 \pm 0,0$ & $0,1 \pm 0,0$ & $<\mathrm{LD}$ \\
\hline Abr & $1,4 \pm 0,3$ & $<\mathrm{LD}$ & $<\mathrm{LD}$ & $0,1 \pm 0,0$ & $0,2 \pm 0,0$ & $0,1 \pm 0,0$ & $0,1 \pm 0,0$ & $0,1 \pm 0,0$ & $<\mathrm{LD}$ & $<\mathrm{LD}$ & $0,1 \pm 0,0$ & $0,2 \pm 0,0$ & $0,1 \pm 0,0$ & $<\mathrm{LD}$ \\
\hline Maio & $1,6 \pm 0,4$ & $<\mathrm{LD}$ & $<\mathrm{LD}$ & $0,1 \pm 0,0$ & $0,2 \pm 0,0$ & $0,1 \pm 0,0$ & $0,1 \pm 0,0$ & $0,2 \pm 0,0$ & $<\mathrm{LD}$ & $<\mathrm{LD}$ & $0,1 \pm 0,0$ & $0,2 \pm 0,0$ & $0,1 \pm 0,0$ & $<\mathrm{LD}$ \\
\hline Jun & $2,5 \pm 0,3$ & $<\mathrm{LD}$ & $<\mathrm{LD}$ & $0,2 \pm 0,0$ & $0,5 \pm 0,0$ & $0,1 \pm 0,0$ & $0,1 \pm 0,0$ & $0,3 \pm 0,0$ & $<\mathrm{LD}$ & $<\mathrm{LD}$ & $0,2 \pm 0,0$ & $0,3 \pm 0,0$ & $0,1 \pm 0,0$ & $<\mathrm{LD}$ \\
\hline Jul & $2,6 \pm 0,4$ & $<\mathrm{LD}$ & $<\mathrm{LD}$ & $0,2 \pm 0,0$ & $0,4 \pm 0,0$ & $0,1 \pm 0,0$ & $0,1 \pm 0,0$ & $0,2 \pm 0,0$ & $<\mathrm{LD}$ & $<\mathrm{LD}$ & $0,2 \pm 0,0$ & $0,3 \pm 0,0$ & $0,1 \pm 0,0$ & $<\mathrm{LD}$ \\
\hline Ago & $5,7 \pm 1,5$ & $<\mathrm{LD}$ & $<\mathrm{LD}$ & $0,2 \pm 0,0$ & $0,6 \pm 0,0$ & $0,1 \pm 0,0$ & $0,2 \pm 0,0$ & $0,4 \pm 0,1$ & $<\mathrm{LD}$ & $<\mathrm{LD}$ & $0,2 \pm 0,0$ & $0,4 \pm 0,0$ & $0,2 \pm 0,0$ & $<\mathrm{LD}$ \\
\hline Set & $3,6 \pm 0,5$ & $<\mathrm{LD}$ & $<\mathrm{LD}$ & $0,3 \pm 0,0$ & $0,4 \pm 0,0$ & $0,1 \pm 0,0$ & $0,2 \pm 0,0$ & $0,4 \pm 0,1$ & $<\mathrm{LD}$ & $<\mathrm{LD}$ & $0,1 \pm 0,0$ & $0,3 \pm 0,0$ & $0,1 \pm 0,0$ & $<\mathrm{LD}$ \\
\hline Out & $2,6 \pm 0,8$ & $<\mathrm{LD}$ & $<\mathrm{LD}$ & $0,1 \pm 0,0$ & $0,3 \pm 0,0$ & $0,1 \pm 0,0$ & $0,2 \pm 0,0$ & $0,2 \pm 0,0$ & $<\mathrm{LD}$ & $<\mathrm{LD}$ & $0,1 \pm 0,0$ & $0,2 \pm 0,0$ & $0,1 \pm 0,0$ & $<\mathrm{LD}$ \\
\hline Nov & $1,3 \pm 0,2$ & $<\mathrm{LD}$ & $<\mathrm{LD}$ & $0,1 \pm 0,0$ & $0,2 \pm 0,0$ & $0,1 \pm 0,0$ & $0,1 \pm 0,0$ & $0,1 \pm 0,0$ & $<\mathrm{LD}$ & $<\mathrm{LD}$ & $0,0 \pm 0,0$ & $0,1 \pm 0,0$ & $0,1 \pm 0,0$ & $<\mathrm{LD}$ \\
\hline Dez & $1,4 \pm 0,3$ & $<\mathrm{LD}$ & $<\mathrm{LD}$ & $0,1 \pm 0,0$ & $0,2 \pm 0,0$ & $0,1 \pm 0,0$ & $0,1 \pm 0,0$ & $0,1 \pm 0,0$ & $<\mathrm{LD}$ & $<\mathrm{LD}$ & $0,0 \pm 0,0$ & $0,1 \pm 0,0$ & $0,1 \pm 0,0$ & $<\mathrm{LD}$ \\
\hline Total & 26,21 & $<\mathrm{LD}$ & 0,2 & 1,8 & 3,6 & 1,0 & 1,4 & 2,6 & $<\mathrm{LD}$ & 0,1 & 1,3 & 2,7 & 1,1 & 0,5 \\
\hline Média & $2,18 \mathrm{aA}$ & $<\mathrm{LD}$ bA & $<\mathrm{LD}$ bA & $0,2 \mathrm{bA}$ & $0,3 \mathrm{bA}$ & $0,1 \mathrm{bA}$ & $0,1 \mathrm{bA}$ & $0,2 \mathrm{aB}$ & $<\mathrm{LD} d \mathrm{~A}$ & $<\mathrm{LD} d \mathrm{~A}$ & $0,1 \mathrm{bA}$ & $0,2 \mathrm{aA}$ & $0,1 \mathrm{bA}$ & $<\mathrm{LD}$ bdB \\
\hline
\end{tabular}

Cada valor mensal corresponde à média de 3 repetições. Para a média mensal, os valores seguidos da mesma letra minúscula entre os metais dentro da mesma área; e maiúsculas para o mesmo metal entre áreas diferentes, não diferem entre si ao nível de 5\% pelo teste de Tukey. 
com a grande concentração encontrada desses elementos no solo, principalmente na área de platô, na qual foi, aproximadamente, $17 \mathrm{x}$ maior que no baixio para o $\mathrm{Al}$ e $2 \mathrm{x}$ maior para o $\mathrm{Zn} .^{17}$

Martins et al. ${ }^{45}$ estudando uma floresta em regeneração submetida a exploração no Pará, verificaram valores médios em $\mathrm{kg} \mathrm{ha}^{-1} \mathrm{ano}^{-1}$ de 0,004 para $\mathrm{Cu}, 0,729$ para $\mathrm{Fe}, 0,167$ para $\mathrm{Mn}$ e 0,016 para $\mathrm{Zn}$. Golley et al.,$^{44}$ em uma floresta tropical úmida, encontraram valores médios em kg ha ${ }^{-1}$ ano $^{-1}$ de 0,01 para $\mathrm{Cu}, 0,5$ para $\mathrm{Fe}, 0,4$ para $\mathrm{Mn}$ e 0,3 para $\mathrm{Zn}$. Os resultados dos diferentes estudos corroboram com os resultados encontrados neste estudo.

A influência temporal na variação dos teores de nutrientes da liteira normalmente é pequena. Esse comportamento já foi relatado por diversos autores. ${ }^{46-49}$ Cunha et al..$^{48}$ afirmaram que a estabilidade nos teores dos elementos demonstra que a qualidade da liteira pouco se altera durante o ano e que, a influência na dinâmica anual de populações de organismos do solo e o fornecimento de nutrientes estão mais relacionados com a quantidade de liteira depositada do que com a variação em sua qualidade.

Estudos como esses servem de alerta para as formas de exploração florestal praticadas, que até pouco tempo extraíam, além dos troncos das árvores, a liteira (usados para energia ou simplesmente queimados para limpeza), fazendo com que fossem exportados uma enorme parte dos nutrientes do solo.

Em suma, dados originados de estudos como os aqui abordados deveriam servir como base quando são elaborados planos de manejo de determinadas formações florestais, visto que onde estão instaladas as florestas tropicais, os solos são geralmente ácidos e de baixa fertilidade, havendo necessidade de se verificar o comportamento da ciclagem dos nutrientes nesses ambientes, já que essas florestas devem ser, na maioria das vezes, de elevada produtividade, levando a uma considerável extração dos nutrientes do solo sem a respectiva reposição. $^{28}$

\section{CONCLUSÕES}

Existe grande variação nas concentrações dos elementos químicos para uma mesma posição topográfica, possivelmente, por influência da decomposição da rocha matriz, devido ao fato de serem ambientes naturais não antropizados e por ser uma região de vegetação heterogênea, com diversas espécies e com diferentes conteúdos de nutrientes.

As áreas de platô obtiveram elevadas concentrações de Mn, $\mathrm{Ni}, \mathrm{Na}, \mathrm{Cu}, \mathrm{Al}$ e $\mathrm{Fe}$, enquanto que as áreas do baixio apresentaram elevadas concentrações de $\mathrm{Ba}, \mathrm{Sr}, \mathrm{Ca}, \mathrm{Zn}$ e $\mathrm{Mg}$. As elevadas concentrações de alguns elementos se dão em função de sua maior disponibilidade no solo para absorção pelas plantas.

A maior concentração do cálcio foi obtida no material lenhoso, o potássio no material reprodutivo, enquanto o sódio e magnésio tiveram as maiores concentrações na fração foliar da liteira para as duas áreas de estudo e nas diferentes estações. Para os micronutrientes, o alumínio foi o elemento de maior predominância em todas as partes da planta, principalmente na estrutura foliar.

A variação temporal na composição química de liteira não teve grande diferença, no entanto, observou-se que o período mais seco da região obteve as maiores concentrações, o que pode ser justificado pelo envelhecimento das folhas, provocado pela fotoinibição e fechamento dos estômatos, e consequente queda da planta para o solo.

Com relação ao retorno anual de elementos químicos para o solo via liteira, dentre os macronutrientes, o cálcio foi o que teve diferença significativa entre os elementos dentro da mesma posição topográfica. Houve diferença significativa para o sódio, quando se analisou o mesmo elemento entre as duas posições, platô e baixio, sendo esse o elemento de menor retorno para o solo. Já o alumínio teve maior representatividade nas áreas de platô, comparando-se o mesmo elemento entre as topografias.

De modo geral, o maior retorno dos elementos químicos para o solo se dá no período seco da região, devido à maior queda da liteira pela parte das plantas ao mesmo tempo que há um maior acúmulo dessa liteira no chão da floresta.

\section{REFERÊNCIAS}

1. Gomes, J. M.; Pereira, M. G.; Piña-Rodrigues, F. C. M.; Pereira, G. H. A.; Gondim, F. R.; Silva, E. M. R.; Revista Brasileira de Ciências Agrárias 2010, 5, 383.

2. Caldeira, M. V. W.; Silva, R. D.; Kunz, S. H.; Zorzanelli, J. P. F.; Castro, K. C.; Godinho, T. O.; Commun. Sci. 2013, 4, 111.

3. Villa, E. B.; Pereira, M. G.; Alonso, J. M.; Beutler, S. J.; Leles, P. S. S.; Floresta e Ambiente 2016, 23, 90.

4. Novais, J. W. Z.; Sanches, L.; Silva, L. B.; Machado, N. G.; Aquino, A. M.; Sallo, F. S.; Ensaios e Ciência: Ciências Biológicas, Agrárias e da Saúde 2017, 21, 178.

5. Almeida, E. J.; Luizão, F.; Rodrigues, D. J.; Acta Amazonica 2015, 45, 157.

6. Biondi, C. M.; Nascimento, C. W. A. do; Fabricio Neta, A. de B.; Ribeiro, M. R.; Revista Brasileira de Ciências do Solo 2011, 35, 1057.

7. Pelozato, M.; Hugen, C.; Campos, M. L.; Almeida, J. A. de; Silveira, C. B. da; Miquelluti, D. J.; de Souza, M. C.; Revista de Ciências Agroveterinárias 2011, 10, 54.

8. Farias, D. T.; Barreto, F. R. S.; Souza, M. R.; Silva, C. J.; Revista Verde 2019, 14, 331 .

9. Malavolta, E.; Manual de Nutrição Mineral de Plantas, $1^{\text {a }}$ ed., Ceres: Piracicaba, 2006.

10. Waraich, E. A.; Ahmad, E.; Ullah, S.; Ashraf, M. Y.; Aust. J. Crop Sci. 2011, 5, 764.

11. Neta, E. F. B.; Nishiwaki, E.; Brazilian Applied Science Review 2018, 2, 1747.

12. Conceição, A. C.; Acta Amazonica, submetido.

13. Biondi, C. M.; Nascimento, C. W. A.; Fabricio Neta, A. B.; Ribeiro, M. R.; Revista Brasileira de Ciências do Solo 2011, 35, 1057.

14. Skoog, D. A.; Princípios De Análise Instrumental, 6a ed., Bookman: Porto Alegre, 2009.

15. Silva, M. L. S.; Vitti, G. C.; Trevizam, A. R.; Pesqui. Agropecu. Bras. 2007, 42, 527.

16. Silva, L. F.; Solos Tropicais: Aspectos Pedológicos, Ecológicos e de Manejo, $1^{\text {a }}$ ed., Terra Brasilis: São Paulo, 1996.

17. Rebelo, A. G. M.; Monteiro, M. T. F.; Ferreira, S. J.; Rios-Villamizar, E. A.; Quesada, C. A. N.; Junior, S. D.; Quim. Nova 2020, 43, 534.

18. Villar, M. L. P.; Manual de Interpretação de Análise de Plantas e Solos e Recomendação de Adubação, 35ª ed., Empaer-MT: Cuiabá, 2007.

19. Raij, B. V.; Fertilidade do Solo e Manejo de Nutriente, $1^{\text {a }}$ ed., International Plant Nutrition Institute: Piracicaba, 2011.

20. Pagano, S. N.; Durigan, G. Em Brasil in Matas Ciliares: Conservação e Recuperação; Rodrigues, R. R.; Leitão Filho, H. F., eds.; EDUSP/ FAPESP: São Paulo, 2000.

21. Caldeira, M. V. W.; Vitorino, M. D.; Schaadt, S. S.; Moraes, E.; Balbinot, R.; Semina: Cienc. Agrar. 2008, 29, 53.

22. Bianchin, J. E.; Dissertação de Mestrado, Universidade Federal do Paraná, Brasil, 2013.

23. Woiciechowski, T.; Tese de Doutorado, Universidade Federal do Paraná, Brasil, 2015.

24. Sloboda, B.; Marques, R.; Blum, H.; Bianchin, J. E.; Donha, C. G.; Silveira, F. M.; Capretz, R. L.; Floresta e Ambiente 2017, 24, 1.

25. Lima, I. V. de; Pedrozo, M. de F. M.; Série Cadernos de Referência 2001, 4, 112.

26. Schützendübel, A.; Polle, A.; J. Exp. Bot. 2002, 53, 1351. 
27. Marafiga, J. S.; Viera, M.; Szymczak, D. A.; Schumacher, M. V.; Trüby, P.; Rev. Ceres 2012, 59, 765.

28. Selle, G. L.; Bioscience Journal 2007, 23, 29.

29. Papenbrock, J.; Mock, H. P.; Tanaka, R.; Kruse, E.; Plant Physiol. 2000, 122, 116.

30. Espig, S. A.; Freire, F. J.; Marangon, L. C.; Ferreira, R. L. C.; Freire, M. B. G. S.; Espig, D. B.; Rev. Arvore 2009, 33, 949.

31. Protil, C. Z.; Marques, R.; Protil, R. M.; Floresta 2009, 39, 699.

32. Schumacher, M. V.; Brun, E. J.; Rodrigues, L. M.; Santos, E. M.; Rev. Arvore 2003, 27, 791.

33. Godinho, T. O.; Caldeira, M. V. W.; Caliman, J. P.; Prezotti, L. C.; Watzlawick, L. F.; Azevedo, H. C. A.; Rocha, J. H. T.; Scientia Forestalis 2013, 41, 131 .

34. Holanda, A. C.; Feliciano, A. L. P.; Freire, F. J.; Sousa, F. Q.; Freire, S. R. O.; Alves, A. L. R.; Ciência Florestal 2017, 27, 621.

35. Jansen, S.; Broadley, M. R.; Robbrecht, E.; Smets, E.; The Botanical Review 2002, 68, 235

36. Schumacher, M. V.; Szymczak, D. A.; Trüby, P.; Londero, E. K.; Marafiga, J.; Ciência Florestal 2018, 28, 532.

37. Pedrozo, M. F. M. Em Cobre; Azevedo, F. A.; Chasin, A. A. M., eds.; Atheneu: São Paulo, 2003, cap. 6.

38. Merian, E.; Metals and Their Compounds in the Environment, $1^{\text {st }}$ ed., VCH: New York, 1991.
39. Luizão, F. J.; Cienc. Cult. (Campinas, Braz.) 2007, 59, 31

40. Hayashi, S. N.; Vieira, I. C. G.; Carvalho, C. J. R.; Davidson, E.; Boletim do Museu Paraense Emílio Goeldi - Ciências Naturais 2012, 7, 283.

41. Brun, E. J.; Schumacher, M. V.; Vaccaro, S. Em Aspectos da Ciclagem do Material Orgânico e Nutrientes na Serapilheira de Florestas Secundárias em Santa Tereza, RS; Schumacher, M. V.; Longhi, S. J.; Brun, E. J.; Kilca, R. V., eds.; Os Autores: Santa Maria, 2011, cap. 10.

42. Viera, M.; Caldato, S.; Rosa, S.; Kanieski, M.; Araldi, D.; Santos, S.; Schumacher, M.; Ciência Florestal 2010, 20, 611.

43. Barajas-Guzmán, G.; Alvarez-Sánchez, J.; Applied Soil Ecology 2003, 24, 91.

44. Golley, F. B.; McGinnis, J. T.; Clements, R. G.; Child, D. L.; Duever, M. J.; Ciclagem de Minerais em um Ecossistema de Floresta Tropical Úmida, $1^{\text {a }}$ ed., EPU/USP: São Paulo, 1978.

45. Martins, W. B. R.; Ferreira, G. D.; Souza, F. P.; Dionisio, L. F. S.; Oliveira, F. A.; Floresta 2018, 48, 37.

46. Cuevas, E.; Medina, E.; Oecologia 1986, 68, 466.

47. Pagano, S. N.; Rev. Bras. Biol. 1989, 49, 633.

48. Cunha, G. C.; Grendene, L. A.; Durlo, M. A.; Bressan, D. A.; Ciência Florestal 1993, 3, 36.

49. Barbosa, J. H. C.; Dissertação de Mestrado, Universidade Federal Rural do Rio de Janeiro, Brasil, 2000. 